\title{
STUDIES OF THE SPIN-ISOSPIN RESPONSE OF NUCLEAK CONTINUUM USING INTERMEDIATE-ENERGY HADRONS
}

\section{Annual Progress Report}

\author{
Dr. F. Todd Baker \\ University of Georgia Research Foundation, Inc. \\ Athens, GA $\mathbf{3 0 6 0 2}$
}

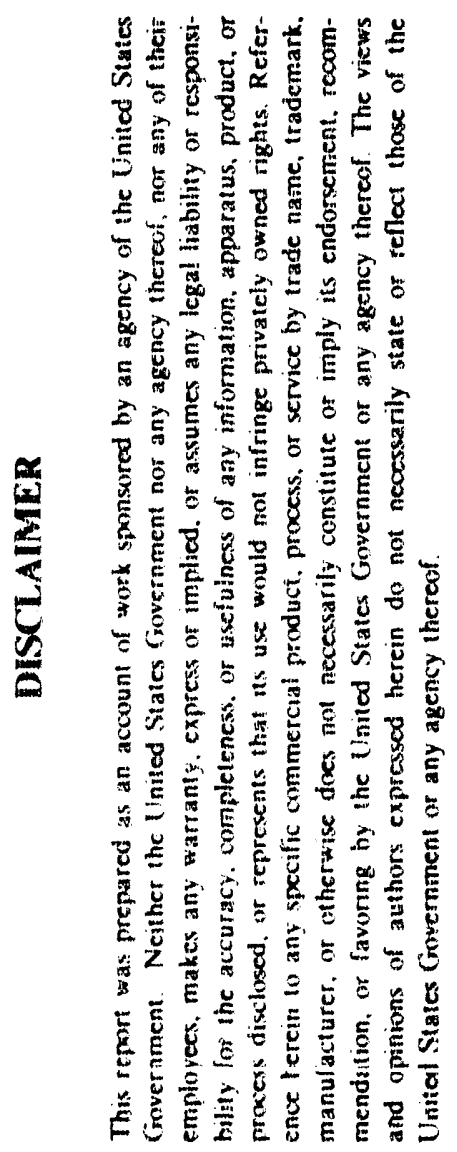

January 1992

PREPARED FOR THE

U. S. DEPARTMENT OF ENERGY

UNDER GRANT

DE.FG 09.87ER40354 


\section{TECHNICAL PROGRESS REPOR'T (1991)}

ANI PLANS FOR 1992

Studies of the Spin-Isospin Response of the Nuclear

Continuum Using Intermediate-Energy Hadrons

F. Todd Baker, Principal Investigator

(DE-FG09-87ER40354)

\section{EXPERIMENTAL ACTIVITY}

During the calendar year 1991, only one experiment was performed:

i) ${ }^{40} \mathrm{Ca}\left(d^{d}, d^{\prime}\right), E_{\mathrm{d}}=400 \mathrm{MeV}$, at SATURNE in May/June 1991.

The idea of this experiment was to use the previously tested signatures of $\Delta S=1, \Delta T=0$ transitions for the $\left(\vec{d}^{\prime} \vec{d}^{\prime}\right)$ reaction to study isoscalar spin strength in ${ }^{40} \mathrm{Ca}$. These data are still being analyzed.

The main reason that there was not more experimental activity in 1991 was that LAMPF had a particularly unproductive year; als is generally well-known, numerous safety' concerns and DOE safety reviews prevented LAMPF from running as usual in 1991. I am spokesman on two pending experiments at LAMPF and participant on several others, but none were scheduled to run in 1991. I am hopeful that at least two of these experiments will be scheduled in 1992 .

\section{PENDING AND APPROVED EXPERIMENTS}

Several experiments are pending:

"Extended Angular Range of $S_{n n}$ Measurements in ${ }^{40} \mathrm{Ca}$ ", for which I am the spokesman, has a high priority (A') in the HRS queue at LAMPF. A proposal update was defended at the PAC in August 1990; the priority was left the same and the allotted time was increased to compensate for the reduced polarization of the new OPPIS polarized ion source. There appears to be a gerd chance that this experiment will be schechuled in 1932. This experiment is an important next step in my program in that it should allow separation of higher multipoles. 
An experiment proposed for the MRS at LAMPF is Experiment 1145, "Measurements of Complete Spin Observables in Quasifree Region". This experiment, to be done at $500 \mathrm{MeV}$, has an A priority; however, the future of experiments at the MRS is currently in doubt since, as a result of the safety reviews last summer, it appears that the MRS can not be safely operated in its present location; it is therefore not very probable that this experiment will be scheduled in 1992.

Another experiment for which I am spokesman is Experiment 1142, "Isovectior/Isoscalar Decomposition for the $\Delta S=1$ Continuum in ${ }^{40} \mathrm{Ca}$ ". Here we have proposed to study the ${ }^{40} \mathrm{Ca}(\overrightarrow{\mathrm{p}}, \overrightarrow{\mathrm{n}})$ reaction at $319 \mathrm{MeV}$ at NTOF at LAMPF. The spin-flip cross section should proceed exclusively via $\Delta T=1, \Delta S=1$; comparing these $(\vec{p}, \vec{n})$ results with our ${ }^{40} \mathrm{Ca}\left(\vec{p}, \vec{p}^{\prime}\right)$ results which should include both $\Delta \mathrm{T}=0$ and $\Delta \mathrm{T}=1$ transitions, we should be able to get information on isoscalar $\Delta S=1$ strength which would serve as an independent measurement with which to compare our ${ }^{40} \mathrm{Ca}\left(\mathrm{d}, \mathrm{d}^{\prime}\right)$ results at SATURNE. This experiment will be updated at the January 1992 PAC meeting; I will show, in that update, that the experiment could be done either at $319 \mathrm{MeV}$ as originally proposed, or at $800 \mathrm{MeV}$ at which we also have $\left(\vec{p}, \vec{p}^{\prime}\right)$ data. This should enhance the probability of having this experiment run in 1992. In fact, there are some interesting advantages which I have discovered for running the experiment at $800 \mathrm{MeV}$ - the expected ratio of isoscalar to isovector responses is considerably larger at $800 \mathrm{MeV} \rightarrow \mathrm{so} I \mathrm{am}$ hopeful that the current priority $\left(\mathrm{B}^{+}\right)$can be increased.

I am a participant for an experiment which was approved by the LAMPF PAC in August 1990 , "Precision Measurement of $D_{n n}$ for ${ }^{13} \mathrm{C}(\vec{p}, \vec{p})$ at $500 \mathrm{MeV}$ ". The idea here is to look for signatures of relativistic effects in the very small spin--nip probabilities of clastic scattering from this odd-A nucleus.

I am also a participant in an update to be submitted to the LAMPF PAC: in Samary. This proposal is to make precision ( w $1 \%$ determinations of elastic scatcering rross sections for angles in $601^{\circ}$. This experiment hat some development time in logl: it 
is likely that shis exputument may run in 1992 also.

Work at SATURNE is expected to continue in the upcoming year. A beam time proposal was submitted in December 1991 to measure tensor polarizations of deuterons scattered from ${ }^{12} \mathrm{C}$. At this stage, the tensor polarimeter is quite small and will therefore measure tensor polarizations for isolated states. However, these measurements should determine the accuracy of approximations which we have made in our analyses ${ }^{1}$ utilizing the vector polarimeter POMME, that the probability of transferring $\Delta S=2$ units of spin to the deuteron is approximately zero and that $P y y \approx A_{y y}$. Data reduction and analysis of already measured ${ }^{12} \mathrm{C}\left(\overrightarrow{\mathrm{d}}, \overrightarrow{\mathrm{d}}^{\prime}\right)$ and ${ }^{40} \mathrm{Ca}\left(\overrightarrow{\mathrm{d}}, \overrightarrow{\mathrm{d}}^{\prime}\right)$ continues.

\section{CONFERENCES ATTENDED}

I attended the International Conference on Spin and Isospin in Nuclear Interactions held in Telluride, Colorado. I coauthored (with C. Glashausser) and presented an invited talk entitled "The Continuum Spin Response to Intermediate-Energy Protons at Low Momentum Transfer".

\section{MAIN RESULTS THIS YEAR}

During 1991 several projects were completed and published.

One paper ${ }^{2}$ presented the results of our ${ }^{40} \mathrm{Ca}\left(\overrightarrow{\mathrm{p}}, \vec{p}^{\prime}\right)$ experiment at $\mathrm{E}_{\mathrm{p}}=800 \mathrm{MeV}$. Here we showed that the $S_{n n}$ data are enhanced relative to the free $N N$ values by the same amount as observed ${ }^{3}$ for $\mathrm{E}_{\mathrm{p}}=319 \mathrm{MeV}$. This supports our previous observations that $\mathrm{S}_{\mathrm{n} n}$ is apparently a robust variable for determining the relative spin response of the nucleus. It is the availability of these data which would now allow us, as mentioned above, to pertorm our proposed $40 \mathrm{Ca}(\vec{p}, \vec{n})$ experiment at $800 \mathrm{MeV}$.

Data for the ${ }^{48 \mathrm{Ca}}\left(\vec{p}, \vec{p}^{\prime}\right)$ reaction at $E_{p}=318 \mathrm{MeV}$ and the ${ }^{44} \mathrm{Ca}\left(\vec{p}^{\prime}, \vec{p}^{\prime}\right)$ reaction at $\mathrm{l}_{\mathrm{w}}=290 \mathrm{MeV}$ were fully analyed and published". The multipole decompositions of the

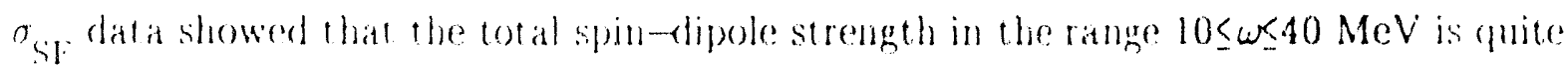
comstant across the calcinm isotopes. However, the $\Delta S=0$ parts of the spectra, of were

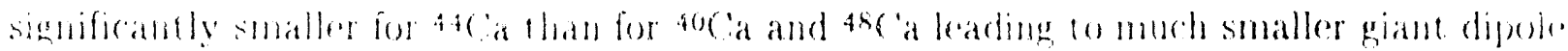


excitation in ${ }^{44} \mathrm{Ca}$.

Analysis of an experiment at KEK in Japan, on which I was a participant, was completed and published 5 in 1991. This experiment was a coincidence experiment, ${ }^{1} \mathrm{H},{ }^{12} \mathrm{C}\left(\mathrm{p} 1 \Delta^{++}\right)$in which the $\Delta^{++}$was detected by observing its decay products in a cylindrical drift chamber surrounding the target. The position of the $\Delta$ peak in the neutron spectrum was found to be dependent on the coincident particles. The peak in coincidence with $\mathrm{p} \pi^{+}$is shifted to lower momenta compared to the free case, whereas in the inclusive spectrum and the spectra in coincidence with other particles it is shifted to higher momenta.

\section{ANALYSES STILL IN PROGRESS}

There are several experiments for which for which we have not yet completed the analyses. These are briefly summarized in this section.

$$
\text { A. }{ }^{12} \mathrm{C}\left(\vec{p}, \vec{p}^{\prime}\right) \text { at } E_{p}=318 \mathrm{MeV}
$$

This experiment, performed at LAMPF, is being analyzed currently. The $\sigma_{\mathrm{SF}}$ data are being analyzed using an extensive set of RPA calculations performed by W. Unkelbach; this is a new approach to the multipole analysis since exploratory calculations indicated that the schematic model which we have used for heavier nuclei was inappropriate for $: 2 \mathrm{C}$. The $\sigma_{0}$ data are being analyzed by Mr. Bruce Storm, a graduate student at the University of Georgia.

$$
\text { B. } 20 \operatorname{spb}\left(\overrightarrow{\mathrm{p}}, \overrightarrow{\mathrm{p}}^{\prime}\right) \text { at } \mathrm{E}_{\mathrm{p}}=200 \mathrm{MeV}
$$

These data, acquired at TRIUMF, have been fully reduced. Analysis and interpretation of the data is being pursued at the University of Georgia.

$$
\text { C. }{ }^{12} \mathrm{C}\left(d_{,} \mathrm{d}^{\prime}\right) \text { at } E_{\mathrm{d}}=400 \mathrm{MeV}
$$

These data, originally accuired primarily to determine if the signature proposed as a $\left(\vec{d}, \vec{d}^{\prime}\right)$ analogue of $S_{n \text { n }}$ for $\left(\vec{p}, \vec{p}^{\prime}\right)$ was useful, were not andyond further. However, data exist for three angles (4. 6and 10 degrees). A gradudte student at (iengia. Mr. Philip Patten.

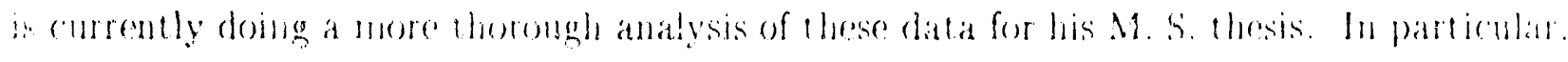


he will use the angular distribution of the soscalar $2 \cdot$ state at $E_{\mathrm{x}} \approx 18 \mathrm{MeV}$ to test an extension of the schematic model for deuterons which I have developed in collaboration with Gary Love. It is possible that some information on the multipole content of the continuum may also be extracted.

$$
\text { D. }{ }^{40} \mathrm{Ca}\left(\overrightarrow{\mathrm{d}}, \overrightarrow{\mathrm{d}}^{\prime}\right) \text { at } \mathrm{E}_{\mathrm{d}}=400 \mathrm{MeV}
$$

These data, acquired last summer, are still being reduced at Saclay. When the data are ready I plan to try to interpret them using my extension of the schematic model.

$$
\text { E. }{ }^{40} \mathrm{Ca}\left(\vec{p}, \vec{p}^{\prime}\right) \text { at } E_{p}=500 \text { and } 580 \mathrm{MeV}
$$

These data and the analyses are being prepared for publication. The experiments provided the data for the Ph. D. dissertation of Andrew Green, Rutgers University.

\section{DISCUSSION OF PLANS FOR 1992}

The general plans for 1992 are given above in Sections II. and V. However, it should be noted here that a major change in my own position occurred in 1991. I was chosen as Head of The Department of Physics and Astronomy, a position which I assumed in July of 1991. This results in two primary changes in this grant. First, my salary is now paid on a twelve month basis so the grant need no longer pay my summer salary. Second, although my experience thus far indicates that I can continue a productive research program in my present position, I find that I cannot concurrently initiate substantially new initiatives on my own; what I desperately need is a postdoctoral research associate. As I have stated in my past proposals, I intend to become active at CEBAF; I am a member of the Hall A Users' Group and have a Memorandum of Understanding with CEBAF committing myself to work on the proton polarimeter for the second arm spectrometer. I propose here to hire a postdoc whose primary responsibility will be to work at CEBAF. However, this can be accomplished with no extra cost to the DOE because of a large anticipated carryover from my 1991 budget. Because my summer salary was not paid in 1991 and becalse travel expenses in 1991 were very low due, primarily, to lack of activity at LAMPl. I anticipate that there will be approxinately $\$ 30.000$ carryover. Thus, the 
total amount requested in my 1992 budget is less than that awarded $(\$ 71,000)$ in 1991 .

\section{GRADUATE STUDENTS}

I currently have two graduate students working for me. Mr. Bruce Storm, who is supported by this grant, passed his Ph. D. preliminary examinations in 1991 and is now a candidate for the degree. It is my hope that one of the two experiments for which I am spokesman at LAMPF will be scheduled this summer and that it will provide the data for a dissertation. Mr. Philip Patton, who was supported by the grant in the summer of 1991 but is not supported by the grant during the academic year, intends only to acquire an M. S. degree. As I indicated above, his M. S. thesis will be a study of the ${ }^{12} \mathrm{C}\left(\mathbb{d}_{\text {, }} \mathfrak{d}^{\prime}\right)$ data. He spent the summer of 1991 at LAMPF, helped in some development runs, and attended the LAMPF summer school for graduate students.

\section{PUBLICATIONS}

\section{REFEREED PAPERS PUBLISHED:}

"The Nuclear Spin Response of ${ }^{40} \mathrm{Ca}$ to $800 \mathrm{MeV}$ Polarized Protons", L. Bimbot et al., Phys. Rev. C42, 2367 (1990).

"Nuclear Response in the ${ }^{54 \mathrm{Fe}}(\overrightarrow{\mathrm{p}}, \overrightarrow{\mathrm{p}})$ Reaction at $290 \mathrm{MeV}$ ", O. Häusser et al., Phys. Rev. C43, 230 (1991).

"Spin Decomposition of the Responses of $44 \mathrm{Ca}$ and ${ }^{48 \mathrm{Ca}}$ to $300 \mathrm{MeV}$ Protons", F. T. Baker et al., Phys. Rev. C44, 93 (1991).

"Coincidence Measurements for ( $p, n)$ Reactions at $1.5 \mathrm{GeV} / \mathrm{c}$ on $\mathrm{C}$ and $\mathrm{H}$ in the $\Delta$ Excitation Region", J. Chiba et al., Phys. Rev. Letters 67, 1982 (1991).

\section{CONFERENCE PROCEDINGS:}

"The Continuum Spin Response to Intermediate Energy Protons at Low Momentum Transfer", F. T. Baker and C. Glashausser, International Conference on Spin and Isospin in Nuclear Interactions (Telluride, Colorado, March 1991), invited talk.

\section{ABSTRACTS}

"Eutude des Transitions Isoscalaires de Spin", E. Tomasi-Gustafsson et al., Congres do la Société Française de Physique, September 1991. 


\section{REFERENCES}

1M. Morlet et al., Phys. Lett. 247B, 228 (1990).

2L. Bimbot et al., Phys. Rev. C42, 2367 (1991).

3F. T. Baker et al., Phys. Lett. 237B, 337 (1990).

${ }^{4}$ F. T. Baker et al., Phys. Rev. C44, 93 (1991).

5J. Chiba et al., Phys. Rev. Letters 67, 1982 (1991).

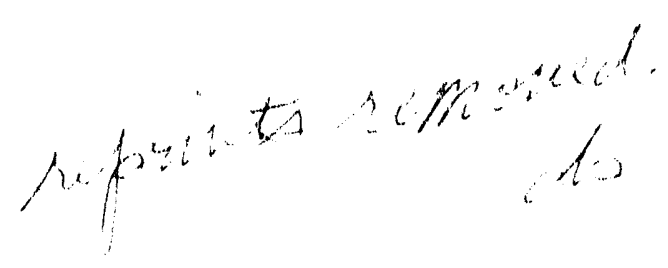



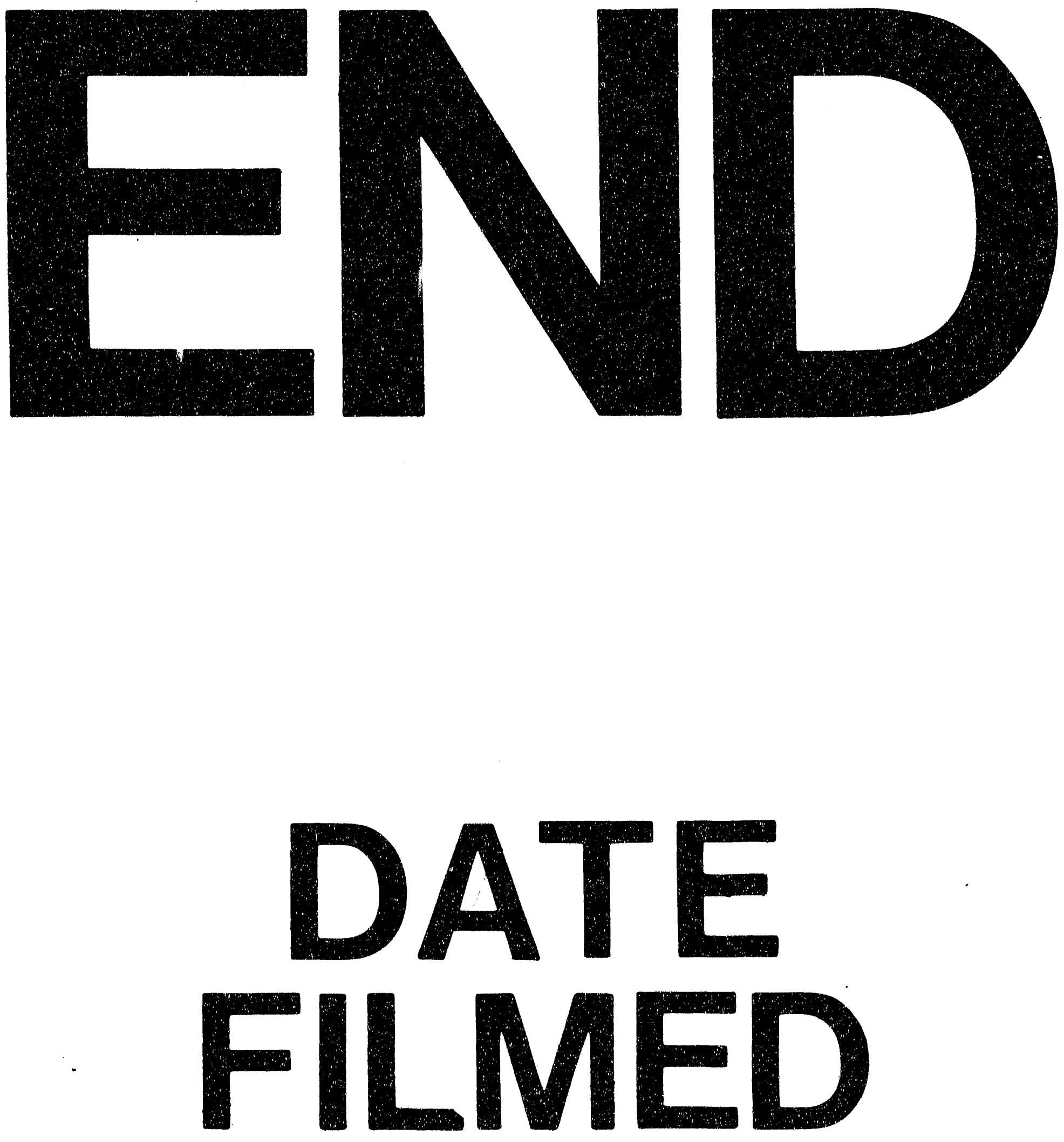

I

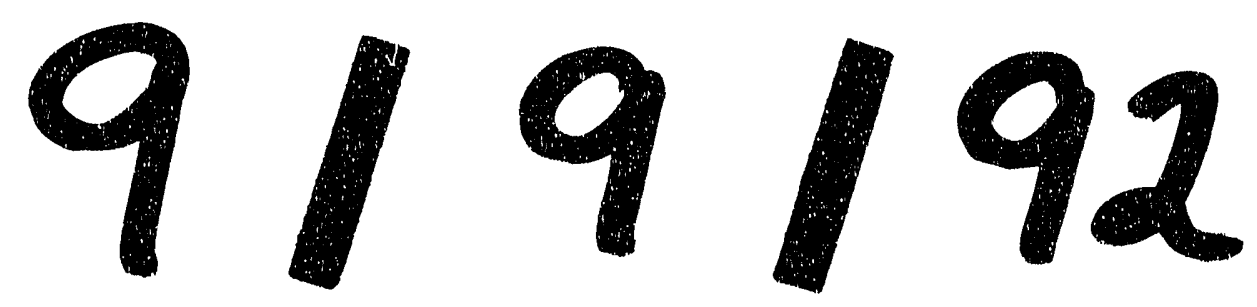


